\title{
Cartografía y obras públicas: el Archivo Histórico Ferroviario de la Fundación de los Ferrocarriles Españoles
}

Raquel Letón Ruiz, Conservación y Archivo Histórico Ferroviario,

Museo del Ferrocarril de Madrid

\section{EL ARCHIVO CON LA DOCUMENTACIÓN SOBRE LA RED DE FERROCARRILES}

El ferrocarril vivió en España, desde su aparición en 1848, una primera etapa de gestión privada que llegó hasta la nacionalización del ferrocarril de vía ancha en 1941. En el desarrollo de este casi siglo de ferrocarril privado se configuraron en nuestro pais diferentes compañías ferroviarias que explotaron los 13.000 kilómetros de red que se construyeron en este periodo. El proceso de concentración empresarial dio como resultado, a finales del siglo XIX, la presencia de tres grandes empresas dominantes: Compañia de los Caminos de Hierro del Norte de España, con 3.800 kilómetros; Compañia de los Ferrocarriles de Madrid a Zaragoza y a Alicante (MZA), de 3.600 kilómetros; y Compañia de los Ferrocarriles Andaluces, con 1.600 kilómetros. El resto de compañias ferroviarias de vía ancha explotaron menos de 500 kilómetros de red. Además de la relevancia de Ferrocarriles Andaluces, otras compañias andaluzas de menor entidad funcionaron durante esta etapa: Ferrocarril de Zafra a Huelva, 180 kilómetros; Compañia de los Ferrocarriles de Lorca a Baza y Águilas, 168 kilómetros, etc.
Además de todas aquellas que fueron progresivamente integrándose en Ferrocarriles Andaluces o en la otra gran compañia que operó en la zona meridional, MZA, cuyas líneas estaban en torno al valle del Guadalquivir. En total, más de 2.000 kilómetros de red andaluza de ferrocarril, de la que se conserva una amplia documentación en el Archivo Histórico Ferroviario.

El Archivo Histórico Ferroviario (AHF) nace en 1979, dependiendo directamente del Consejo de Administración de la Red Nacional de los Ferrocarriles Españoles (RENFE) e integrándose en su Secretaría. En 1985, con la creación de la Fundación de los Ferrocarriles Españoles, el archivo inicia su etapa actual cuya principal función es recoger, organizar, evaluar, gestionar y difundir el patrimonio documental ferroviario. En 2010, el AHF se integró, junto con la Biblioteca Ferroviaria, en el Museo del Ferrocarril de Madrid, consiguiendo con esta simbiosis un marco excepcional e inigualable del patrimonio museológico, bibliográfico y documental ferroviario.

El Archivo, como heredero de los fondos documentales de antiguas compañias ferroviarias y de la propia RENFE, es en la actua-

Plano del proyecto de la línea de ferrocarril de Sevilla a Cádiz del ingeniero Glo Hermans, año 1852. Fuente: Archivo Histórico Ferroviario, 22-3

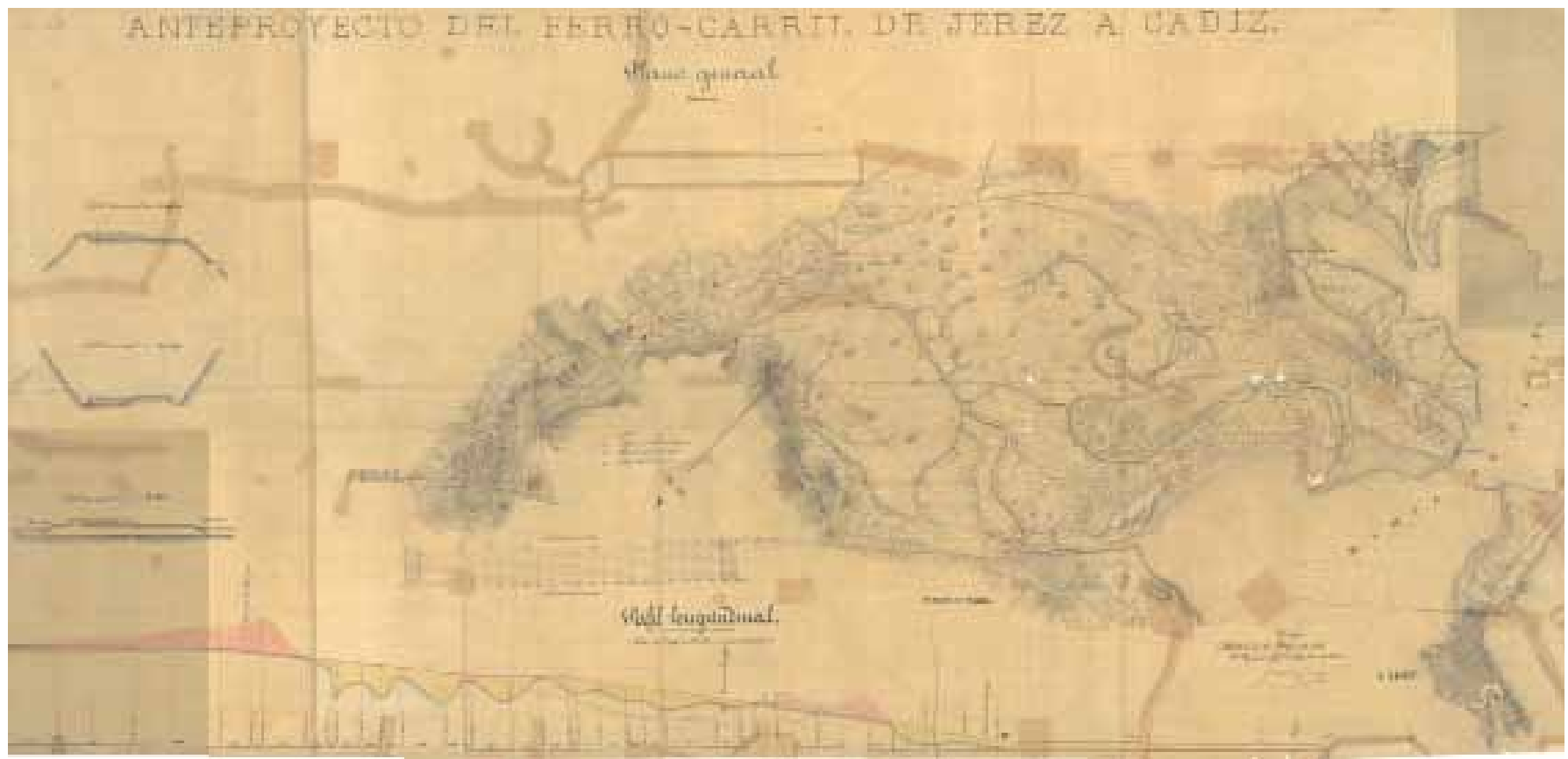




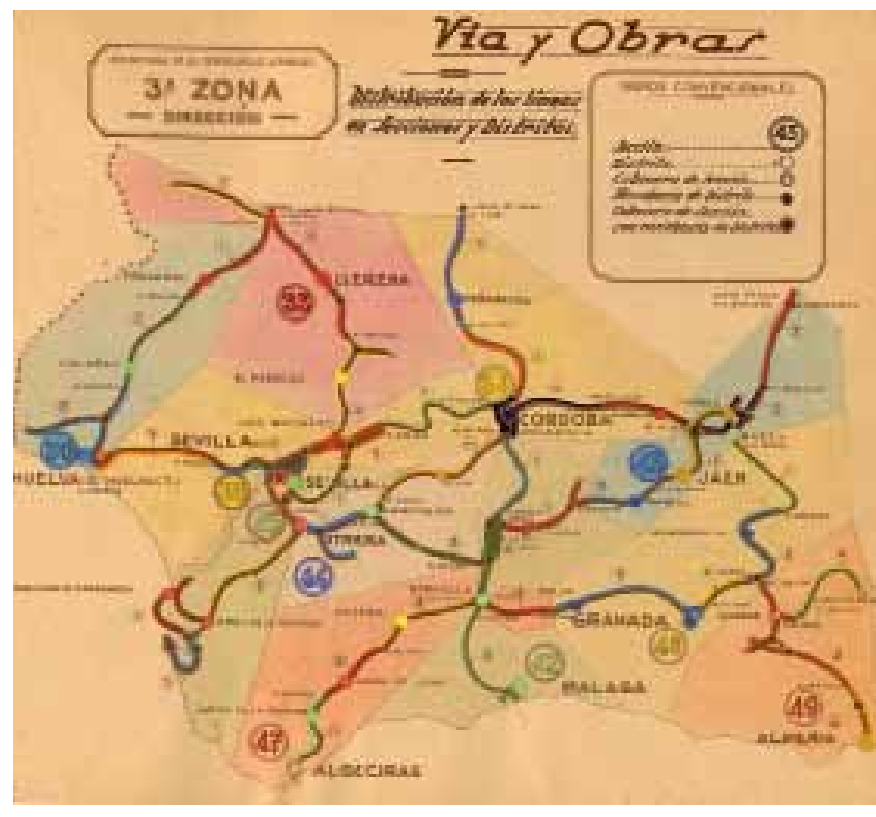

Mapa de la organización del Servicio de Vía y Obras en la Tercera Zona de RENFE, año 1948. Fuente: Biblioteca Ferroviaria, MR-25

lidad el más importante archivo español sobre las empresas ferroviarias que operaron en nuestro país en el denominado periodo privado. El ingreso de los fondos se produjo, fundamentalmente, en el momento de su constitución. A estos se añadieron otros fondos que la empresa estatal ferroviaria consideró en ese momento como merecedores de tal fin.

\section{EL MATERIAL CARTOGRÁFICO Y LOS MAPAS DE ANDALUCÍA}

El desarrollo ferroviario en el mediodia peninsular fue realmente significativo $y$, en lo que hoy conocemos como la Comunidad Autónoma de Andalucia, se configuró una importante red ferroviaria articulada con tres objetivos básicos: el transporte interior de la producción agraria y el suministro urbano; la creación de unos ejes perpendiculares a la costa orientados a los tráficos mineros de exportación; y la consolidación de un mercado nacional con el que conectaba a través de los enlaces de la ruta de la Plata ferroviaria, el valle del Guadiato, el valle del Almanzora y el paso de Despeñaperros, el más importante, que

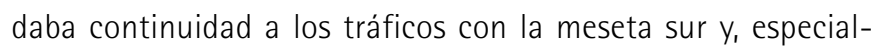
mente, con Madrid.

La documentación cartográfica constituyó desde su origen un elemento directamente vinculado con el ferrocarril, hasta el punto de que es en el ámbito de las comunicaciones, junto al militar, donde se han desarrollado muchos de los proyectos cartográficos producidos a lo largo de la historia. En el siglo XIX, a la hora de establecer los primeros trazados de las líneas ferroviarias que se iban incorporando a nuestro complicado relieve, los ingenieros hubieran deseado contar con una cartografía básica de calidad, pero, dado que esos mapas no existían, fueron los planos que obligatoriamente debian incluirse en los proyectos de los trazados los que en la mayoría de los casos aportaron información a los cartógrafos y no al contrario. La primera cartografía ferroviaria comunicaba la evolución de la red que se iba construyendo y el dominio del territorio que este nuevo medio de transporte iba conquistando, era una herramienta que permitía a la administración central y a los organismos locales afianzar y planificar su políticas y estrategias a la hora de proyectar las lineas'.

La documentación cartográfica andaluza existente en el AHF se centra mayoritariamente en las líneas de vía ancha que se construyeron entre 1851 y la nacionalización la red en $1941^{2}$. Se conserva una amplia planimetria de los distintos proyectos ferroviarios andaluces, realizados o no, que sirvieron para la progresiva apertura de tramos en esta zona. Localizados principalmente en el fondo de MZA, como compañia que agrupó empresarialmente a distintas lineas andaluzas, dentro de sus series del Servicio de Vía y Obras (Red Antigua), Servicio de Estudios y Proyectos y del Servicio Comercial. Por su parte, la Compañía de los Ferrocarriles Andaluces ofrece un amplio repertorio centrado en los planos del Servicio de Vía y Obras.

La descripción de los fondos relativos a Andalucía del AHF puede consultarse a través del portal Docutren (www.docutren.com). Por último, es obligado hacer alusión a la importante colección cartográfica conservada en la Biblioteca Ferroviaria de nuestra institución, donde se conservan 330 mapas ferroviarios, desde mediados del siglo XIX hasta la actualidad.

\section{Notas}

' La cartografía básica se desarrolló a partir de los trabajos de Francisco Coello en 1849, un año después de que se inaugurara el primer ferrocarril peninsular entre Barcelona y Mataró, empezó a publicar el Atlas de España y sus posesiones de Ultramar, que cartografiaba una parte importante del territorio. Su vinculación con los ferrocarriles y su trazado culminó en 1855 con su obra Proyecto de las líneas generales de navegación y de ferrocarriles en la Península Española (esta publicación puede consultarse en la Biblioteca Ferroviaria).

${ }^{2}$ Destacan los pioneros planos de mediados del siglo XIX de los ingenieros Glo Hermans, Rafael Sánchez Mendoza, Constantino de Ardanaz, José Soler de Mena o Ángel Mayo.

\section{Bibliografía}

CABANES MARTíN, A.; LETÓN RUIZ, R.; SEVILLANO QUEIPO DE LLANO, R. (2008) El ferrocarril en sus mapas: estudio del patrimonio cartográfico ferroviario en España. Patrimonio Cultural y Derecho, n. ${ }^{\circ} 12,2008$, pp. 123-202 CUADROS TRUJILLO, F.; CUÉLLAR VILLAR, D. (2009) El segundo impulso ferroviario en Andalucia (1880-1940): documentos e historia. Cuadernos del Archivo Histórico Ferroviario, n. ${ }^{\circ}$ 4, 2009

CUÉLLAR VILLAR, D. (2008) La construcción de las primeras líneas ferroviarias en Andalucia (1851-1880). Cuadernos del Archivo Histórico Ferroviario, n. ${ }^{\circ}$, 2008

CUÉLLAR VILLAR, D.; LETÓN RUIZ, R. (2004) La Historia del Ferrocarril a través de los Fondos Documentales de Via y Obras, 1848-1941. Cuadernos del Archivo Histórico Ferroviario, n. ${ }^{\circ}$, 2004 